\title{
Reputação online dos spas de Foz do IguaçU - PR, Brasil
}

\author{
Online reputation of spas at Foz do Iguaçu-PR, Brazil
}

Dartilene de Souza e Silva (dartilene1905@hotmail.com)

Mestranda em Turismo, bacharel em Turismo, Universidade Federal do Paraná - UFPR, Curitiba - PR

José Manoel Gonçalves Gândara (jmggandara@yahoo.com.br)

Doutor, bacharel em Turismo, professor e pesquisador do Mestrado em Turismo e do Mestrado e Doutorado em Geografia, Universidade Federal do Paraná - UFPR, Curitiba - PR

\section{RESUMO}

A procura pela melhora da qualidade de vida tem contribuído para o crescimento do interesse pelos spas que, nesse caso, se apresentam como espaços dentro dos resorts dedicados a massagens, terapias e banhos diferenciados para os hóspedes. A reputação online está associada a consequência da avaliação do consumidor do mundo social na internet, relacionada à sua experiência e satisfação pelo serviço recebido. Sendo assim, o objetivo desse artigo foi analisar a qualidade experiência do hóspede nos spas de Foz do Iguaçu através da reputação online no website TripAdvisor. Como metodologia empregou-se a revisão e análise bibliográfica, bibliométrica e sistemática sobre as temáticas: turismo de saúde e spas, experiência, qualidade e reputação online, bem como uma investigação documental de entidades públicas e netnográfica utilizada para análise e pesquisa dentro do mundo virtual da Internet dos comentários publicados pelos hóspedes no website TripAdvisor em julho de 2015. Entendendo qualidade como sendo o resultado da comparação entre a expectativa pelo serviço a ser recebido e a percepção daquilo que the foi entregue, os resultados desse estudo apontam que a maior parte dos hóspedes teve uma experiência positiva nos empreendimentos sendo os aspectos mais comentados: o restaurante, o atendimento e os atrativos do resort. Os pontos 
negativos ressaltaram o preço, que tem relação com a estética e as facilidades, informações e serviços que se referem à evasão que conduz o visitante à imersão na atividade e à perda da noção do tempo por sua capacidade de envolvimento relacionado à emoção e aos cinco sentidos humanos sendo componentes importantes para a experiência turística para que a mesma se converta em algo diferenciado e único. Os spas receberam poucas avaliações específicas, sendo compreendidos como mais uma atração do resort e não como a principal motivação da viagem.

Palavras-chave: Qualidade; Reputação online; Spa.

\section{ABSTRACT}

The search for improvement of quality of life has contributed to the growth of interest in spas that, in this case, are spaces built inside the resorts dedicated to massages, therapies and differentiated baths for guests. Online reputation is associated with the result of the evaluation of internet consumer, related to their experience and satisfaction with the services received. Therefore, the objective of this work was to analyse the quality of the guest experience at the spas of Foz do Iguaçu from the TripAdvisor website. The methodology applied was a bibliographical review and analysis, and systematic about the Bibliometric themes: healthy tourism and spas, experience, quality and reputation online, as well as a documentary investigation of public entities and netnography used for analysis and research within the virtual world of Internet on comments published by the website TripAdvisor in July 2015. Understanding quality as being the result of the comparison between the expectation and the service to be received and the perception of what has been delivered, the results of this study indicate that most of the guests had a positive experience, having been the most discussed aspects: restaurant, service and attractions of the resort. The negative points stressed price, related to aesthetics and facilities, information and services relating to the evasion that leads the visitor to an immersion in the activities and loss of sense of time by its ability of involvement related to emotions and the five human senses that are important components for the tourist to experience something unique and differentiated. The spas 
have received few reviews, being understood as an attraction of the resort and not as the main motivation for the trip.

Keywords: Quality; Online reputation; Spa.

\section{INTRODUÇÃO}

As viagens realizadas por motivo de saúde podem ter como objetivo realizar tratamentos, exames e cirurgias médicas e odontológicas para curar doenças ou melhorar a estética, caracterizando-se como turismo médicohospitalar, ou buscar uma vida mais saudável por meio da diminuição do estresse, redução do peso corporal e prevenção de doenças, configurandose turismo de bem-estar praticado em spas, clínicas naturistas e em estâncias termais e hidrominerais (MTUr, 2010; ABRATUS, 2015; PRTur, 2014).

Esse trabalho enfatiza o turismo de saúde que ocorre nos spas, configurado como de bem-estar. Segundo Chon e Sparrowe (2003) há os resorts que são spas porque possuem estrutura de resort com o objetivo de spa (focados nos tratamentos para perda de peso, redução do estresse e relaxamento) e os spas dentro dos resorts, onde, além da oferta gastronômica e das atividades sociais e de lazer, oferecem massagens, aulas de ginástica e banhos diferenciados aos hóspedes (CHON e SPARROWE, 2003, p. 284-285).

Considerando como problema de pesquisa compreender quais são os aspectos mais importantes e o grau de satisfação dos clientes que frequentam esses empreendimentos é que se definiu como objetivo desse trabalho analisar a qualidade da experiência do hóspede nos spas de Foz do Iguaçu através da reputação online no website TripAdvisor, tendo como objetos de estudo os comentários sobre os empreendimentos Mabu Thermas Grand Resort, Bourbon Cataratas Convention \& Spa Resort, Nadai Confort Hotel \& Spa, Recanto Cataratas Thermas Resort \& Convention, San Martin Resort \& Spa e Belmond Hotel das Cataratas.

Nesse estudo os empreendimentos avaliados estão localizados no município de Foz do Iguaçu, situado no extremo oeste do Estado do Paraná, na divisa do Brasil com o Paraguai e a Argentina. "A cidade é centro turístico e econômico do oeste do Paraná e é um dos mais importantes destinos 
turísticos brasileiros" possuindo importantes atrativos turísticos como as Cataratas do Iguaçu - uma das Sete Maravilhas da Natureza e o Complexo Turístico de Itaipu, que abriga a Hidrelétrica de Itaipu (PREF. MUNICIPAL DE FOZ DO IGUAÇU, 2015). Destaca-se também como o segundo destino de turistas estrangeiros no país e o primeiro da região sul (ADETUR CATARATAS E CAMINHOS, 2016).

A qualidade dos serviços em meios de hospedagem vem sendo estudada por meio de três grupos de investigação, conforme explicam Santomá Vicens e Costa Guix (2007), aqueles que analisam o conceito a partir de um ponto de vista teórico, aqueles que investigam a gestão da qualidade total e aqueles que pretendem medir a qualidade dos serviços. Nesse último caso, a qualidade é medida preponderantemente comparando-se a expectativa do hóspede pelo serviço recebido e a sua percepção quanto as ações das empresas fornecedoras do mesmo (PARASURAMAN, ZEITHAML \& BERRY, 1988; SANTOMÁ VICENS e COSTA GUIX, 2007). Gândara, Fraiz Brea e Manosso (2013) destacam quanto à qualidade da experiência, que a reputação online é a opinião dos consumidores sobre as experiências e satisfação propagada nos meios virtuais sobre determinada empresa e por isso deve ser considerada um instrumento importante para avaliar a qualidade dos serviços (GÂNDARA, FRAIZ BREA e MANOSSO, 2013).

Como metodologia a respeito dos temas turismo de saúde e spas, experiência, qualidade e reputação online, realizou-se nas bases Publicações de Turismo e Redalyc uma revisão e análise bibliográfica, bibliométrica e sistemática buscando identificar, sistematizar e compreender a literatura existente que é usada tanto em pesquisas qualitativas quanto quantitativas e mistas, com diferentes enfoques (CRESWELL, 2010; ALVARENGA, 1998; ALBACH, 2015). Também se empregou a pesquisa documental em documentos de entidades públicas (MARTINS e THEÓPHILO, 2009) e netnográfica que é aquela utilizada para análise e pesquisa dentro do mundo virtual da Internet (TAFARELO, 2013). Foram considerados os comentários publicados pelos hóspedes dos spas de Foz do Iguaçu na website Tripadvisor. O recorte 
temporal adotado foi o mês de julho de 2015 (comentários com data de postagem entre 01 a 31/07/2015), quando o movimento de passageiros no Aeroporto Internacional de Foz do Iguaçu teve 196.405 embarques e desembarques, apresentando um aumento de $21 \%$ na comparação com o mês anterior (junho/2015) e 14\% superior ao registrado em julho de 2014, perío do da Copa do Mundo no Brasil (ITAIPU BINACIONAL, 2015).

O modelo empregado para avaliar a qualidade da experiência dos hóspedes foi desenvolvido por Gândara, Fraiz Brea e Manosso (2013) utilizado para analisar a qualidade da experiência dos hotéis termais da Galícia (Espanha). Tal método foi desenvolvido a partir dos Domínios da Experiência de Pine II \& Gilmore (1999): 1. Estética (elementos que fazem com que o indivíduo tome a decisão de entrar em um local e ali permanecer), 2. Evasão (capacidade de fazer com que o consumidor fique imerso nas atividades que Ihe são propostas), 3. Aprendizagem (essencialmente ativa, pois aprender algo requer total participação do sujeito envolvido e envolve tanto a perspectiva sensorial quanto intelectual) e 4. Entretenimento (aspecto mais passivo da experiência, pois designa um estado de resposta aos elementos que Ihe são apresentados); também do método SERVQUAL de Parasuraman, Zeithaml \& Berry $(1988 ; 1994)$ com 5 domínios: Tangibilidade, Confiabilidade, Disponibilidade, Segurança e Empatia, e mais 22 itens, e ainda da adaptação HOTELQUAL feita por Costa \& Rita (2010) y Blešiš et al (2011) com 24 itens para a hotelaria.

Esse trabalho analisou vinte categorias: paisagem, edifício, limpeza, entorno, localização, quartos, instalações, preço, conforto, restaurante, facilidades, informações, horários, serviços, funcionários, atividades, terapias e tratamentos, spa, atrativos e espaço kids dentro dos quatro Domínios da Experiência de Pine II \& Gilmore (1999).

\section{TURISMO DE SAÚDE E SPAS}

A busca por um estilo de vida mais saudável e o crescimento do culto a boa forma impulsionaram o mercado a investir em saúde com a oferta de 
exames, cirurgias e terapias, e motivaram as pessoas a se deslocarem para tratamentos de saúde, estética e bem-estar (CHON e SPARROWE, 2003; BONFADA, BONFADA, GÂNDARA, FRAIZ BREA, 2008; GÂNDARA, FRAIZ BREA e MANOSSO, 2013; MANOSSO, SILVA, BIZINELLI e GÂNDARA, 2016). Para 0 Ministério do Turismo - MTur (2010) os fatores que caracterizam o Turismo de Saúde são a necessidade de se realizar tratamentos médicos e a vontade de ter uma vida mais saudável.

O turismo de saúde pode ser do tipo médico-hospitalar, quando envolve tratamentos médicos, exames e cirurgias, ou de bem-estar para quem procura descanso e/ou uma vida saudável (MTUR, 2010; BONFADA, BONFADA, GÂNDARA e FRAIZ BREA, 2008; BONFADA, BONFADA, FRAIZ BREA e GÂNDARA, 2011; ARAGONES, PAYARES e NAVAS, 2012) e abrange todas as etapas da viagem: a oferta de serviços, equipamentos e produtos que possibilitam o transporte e a estada do indivíduo, assim como agenciamento, alimentação, recepção e entretenimento (ABRATUS, 2015).

O termo spa não tem uma única origem, derivando ou de uma cidade da Bélgica chamada Spa situada na província de Liège que possuía uma fonte de água mineral muito conhecida, ou dos banhos para a "cura pela água" ("Salut per Aqua" ou "Solus per Aqua") (ABC SPAS, 2015; BONFADA et al, 2008; BONFADA et al, 2011 ). Aragones, Payares e Navas (2012) relatam que o uso de águas minerais e termais para tratamento de doenças é muito antigo, pois já nos anos 4.000 a.C. existiam peregrinações até os templos da Mesopotâmia a fim de diagnosticar doenças que eram tratadas nos centros de saúde com águas termais de Sumeria. Também se tem relatos do uso de águas termais desde o Império Romano na Península Ibérica e na Grécia, usadas tanto como remédio (via oral) quanto em forma de banhos (VARGAS e GIL, 2002; DE LA ROSA e MOSSO, 2004 apud EZAIDI, KABBACHI, EL YOUSSI, 2007; PACHECO e ROJAS, 2014) Paixão (2007) conta que já no século I a.C. haviam na cidade de Roma 170 termas e três séculos mais tarde já somavam mais de mil que movimentavam milhares de pessoas, e que no ano 300 havia cerca de mil termas, dentre Vichy na França, além de Aachen (ou Aix-la- 
Chapelle) e Baden-Baden, na Alemanha (MTUR, 2010). No século XIX, eram tantos os deslocamentos para tratamentos em estâncias hidrominerais que esses começaram a ter um caráter turístico, ou seja, além da busca pelo bemestar físico e mental por meio dos tratamentos, também o bem-estar social pela interação com a atividade turística (MTUR, 2010).

Assim esse mercado de spa se espalhou pelo mundo e continua apresentando crescimento na mesma medida em que os seres humanos buscam melhorar a saúde e o equilíbrio entre corpo, mente e espírito, por meio de tratamentos corporais de prevenção e cura, terapias de bem-estar, relaxamento e beleza, banhos e rituais de purificação corporal e mental, práticas nutricionais e medicinais, além de outras atividades e exercícios (ABC SPAS, 2015). De acordo com um estudo da Stanford Research International, o Brasil possuía em 2007, 643 spas, entre hotéis/spas e spas urbanos (MTUR, 2010).

Com o aumento da demanda pela melhora da saúde e a combinação dos serviços terapêuticos praticados por diversas culturas do mundo sendo ofertados num mesmo espaço surgiu o conceito mais moderno de spa, tendo grande contribuição dos Estados Unidos, a partir do momento em que eles se adaptaram aos interesses e necessidades da população regional incluindo tratamentos nutricionais e atividades aeróbicas para a redução do peso e tratamentos de beleza permitindo a harmonização do corpo com os sentidos aliando saúde e beleza (DUSSEAU e BRENNAN, 2008; SPA FINDER, 2014; ABC SPAS, 2015; HEYES, BEARD e GEHRELS, 2015).

Não há uma concepção única sobre spa, mas o objetivo desses espaços é tratar corpo, mente e espírito por meio de vários serviços e atividades buscando saúde, prevenção, bem-estar e cuidados com o corpo (ABC SPAS, 2014; BONFADA et al, 2008; MANOSSO et al, 2016). Segundo a classificação da Associação Brasileira de Clínicas e Spas, os spas são "estruturas com hospedagem e alimentação focadas na promoção do bemestar e qualidade de vida" (ABC SPAS, 2015), ou seja, são empreendimentos ou espaços que oferecem bem-estar por meio de tratamentos com água ou a ela relacionados, além de outros tratamentos ligados à saúde, à estética e à beleza, como: banhos especiais, massagens, tratamentos, exercícios, 
alimentação balanceada, programas dietéticos e físicos, entre outros (BONFADA et al, 2008; BONFADA et al, 2011), visando proporcionar relaxamento, vitalidade e saúde aos seus consumidores (DUSSEAU e BRENNAN, 2008).

Para Chon e Sparrowe (2003) há os resorts que são spas, ou seja, oferecem a estrutura de um resort mas com o objetivo de um spa, onde os hóspedes estão focados nos tratamentos para perda de peso, redução do estresse e relaxamento, sem ter de competir com a oferta gastronômica e de lazer dos hotéis comuns. Eles afirmam que há também os spas dentro dos resorts, cujas instalações oferecem atividades sociais e de lazer tradicionais dos resorts, além de oferecer terapias como massagens, aulas de ginástica e banhos especiais e relaxantes aos visitantes (CHON e SPARROWE, 2003). Vale ressaltar que no Brasil, segundo Bonfada et al (2011), os spas estão mais orientados ao ócio, à beleza e ao relaxamento.

\section{A QUALIDADE NA HOTELARIA}

O conceito de qualidade e suas estratégias de implantação se deram incialmente na indústria, sendo, posteriormente, expandidas para o setor de serviços (DELGADO, 1997).

O termo qualidade é conceituado por vários autores. Crosby (1987) define qualidade como a conformidade com as especificações, cumprindo com os requisitos e entende que a principal motivação da empresa é não ter defeitos. Juran e Gryna (1993) definem qualidade como adequação ao uso, referindo-se à qualidade ao atendimento das especificações pré-definidas para o desenho do produto e a sua conformidade. Cronin e Taylor (1992) defendem que a qualidade percebida dos serviços antecede à satisfação do cliente, e que essa satisfação tem efeito significativo nas intenções de compra. O entendimento mais aceito sobre o conceito de qualidade é o atendimento das exigências do cliente (DIAS e PIMENTA, 2005) e que compara as expectativas dos clientes com a sua percepção do serviço recebido (SANTOMÁ VICENS e COSTA GUIX, 2007). 
Delgado (1997) comenta os resultados de um estudo sobre Gestão, encomendado pela Fundação Europeia, que diz que as quatro razões porque diretores consideram a qualidade importante são: 1) ela é o primeiro argumento de compra, 2) é um dos principais meios de redução dos custos, 3) é um dos principais meios de implementar a flexibilidade/capacidade de resposta, 4) é um dos principais meios de redução do tempo em todos os aspectos. Parasuraman Zeithaml e Berry (1985) alertam que a qualidade na prestação dos serviços necessita de uma atenção especial pelas próprias características dos serviços: intangibilidade, heterogeneidade e inseparabilidade entre produção e consumo.

A hotelaria é de fundamental importância no turismo por tratar do acolhimento e prestação de serviços para pessoas fora das suas residências. Como empreendimentos hoteleiros, tem-se os hotéis, as pousadas, os hotéis fazenda, os hotéis históricos, os flats/aparts, os cama e cafés e os resorts, que segundo o MTur (2010) são os hotéis com infraestrutura de lazer e entretenimento que disponibilizam serviços de estética, atividades físicas, recreação e convívio com a natureza no próprio empreendimento. Os empreendimentos hoteleiros estão em constante mudança para acompanhar a evolução do mercado e suas exigências, buscando implantar novas tecnologias, atender seus clientes com excelência e melhorar a qualidade de seus serviços, pois um serviço de qualidade incide diretamente sobre a satisfação do cliente (GETTY e THOMPSON, 1994).

\footnotetext{
"A gestão pela qualidade está diretamente associada às oportunidades de fornecimento de serviços que visam à excelência da performance, à satisfação do cliente, à melhoria da produtividade e da eficiência através da redução máxima de custos, além da necessidade de aumento participativo no mercado". (BARBALHO e BARBOSA, 1997 apud DIAS e PIMENTA, 2005, p. 84)
}

Mudanças no setor de hospitalidade, tais como mercado mais competitivo, consumidor mais exigente, ampliação e diversificação dos serviços, adequação a vários perfis e gostos de consumidores (FLORES, 2004) exigiram flexibilidade dos processos e inovação na melhoria dos produtos e da prestação dos serviços (HARVEY, 1996). Para Dias e Pimenta (2005) a gestão 
da qualidade traz para a empresa, uma vantagem competitiva diante de seus concorrentes por ser um fator decisivo na escolha do cliente que avalia a qualidade de um produto turístico como um todo, pelas próprias características dessa atividade, seus componentes específicos são considerados quando há falha em algum deles. Reisinger (2001) afirma que os serviços turísticos e hoteleiros têm uma alta dependência da satisfação do cliente. A insatisfação é um dos principais motivos da perda de clientes, conforme a pesquisa realizada em hotéis de Hong Kong, onde os autores Qu, Ryan e Chu (2000) identificaram seis fatores que impactaram significativamente na satisfação dos hóspedes quanto à qualidade dos serviços, destacando-se a qualidade do atendimento dos funcionários, seguido de qualidade das instalações, da razão custo-benefício, da variedade e eficiência dos serviços, outros serviços relacionados e proteção e segurança (QU, RYAN e CHU, 2000). Diversos estudos sobre a qualidade dos serviços em meios de hospedagem têm demonstrado uma relação positiva entre a qualidade do serviço, a satisfação do hóspede, a intenção de compra e a recomendação posterior (SANTOMÁ VICENS e COSTA GUIX, 2007).

Buscando aferir a qualidade dos serviços, Oliver (1981) apresentou o modelo "expectancy-disconfirmation" para estudar a satisfação do cliente, entendendo que os clientes se sentem satisfeitos com o consumo de um produto ou serviço como resultado da comparação subjetiva entre as expectativas prévias ao consumo e a percepção posterior ao consumo. Para Cronin e Taylor (1992) a qualidade está relacionada a uma atitude do cliente com relação às dimensões da qualidade, e que, portanto, devem ser medidas como uma percepção de desempenho. Grönroos (1988) e Parasuraman, Zeithaml e Berry (1988) defendem o conceito de que qualidade é a diferença entre as expectativas ou desejos dos clientes (serviço esperado) e suas percepções (serviço percebido), ou seja, a qualidade é o resultado da comparação entre a expectativa pelo serviço a ser recebido e a percepção das ações das empresas fornecedoras do mesmo (PARASURAMAN, ZEITHAML \& BERRY, 1988; GRÖNROOS, 1988). O modelo de escalas proposto por 
Parasuraman, Zeithaml y Berry (1985) denominada SERVQUAL, também conhecido como "the gap model" (ALLEN GONZÁLEZ, GÂNDARA, FRAIZ BREA, 2006) é usado para medir a qualidade percebida a partir das expectativas dos clientes. Destaca-se, que a partir do modelo SERVQUAL, surgiram outros modelos adaptados, tendo como objetivo a medição da qualidade dos serviços prestados baseados no modelo de Parasuraman, Zeithaml \& Berry (1988), como o LODGSERV (KNUTSON et al., 1990), o LODGQUAL (GETTY \& THOMPSON, 1994) e o HOTELQUAL (FALCES et al., 1999) utilizados para medir a qualidade de serviços meios de hospedagem, o DINESERV para restaurantes (STEVENS, KNUTSON E PATTON, 1995), o SERVPERF similar a o SERVQUAL (CRONIN \& TAYLOR, 1992).

Muitos estudos sobre a qualidade nos serviços turísticos utilizam como base o modelo SERVQUAL de Parasuraman, Zeithaml \& Berry (1988) onde a qualidade do serviço é medida por uma escala de 22 itens divididos em 5 domínios. Esses estudos têm como principal objetivo medir a qualidade do serviço e determinar quais são os atributos do serviço que afetam as percepções e expectativas dos clientes dos meios de hospedagem (SANTOMÁ VICENS e COSTA GUIX, 2007). Veiga e Farias (2005) realizaram um estudo de caso para avaliar a qualidade dos serviços prestados por uma pousada no litoral nordestino, por meio da análise da lacuna (GAP) existente entre as expectativas e percepções do cliente, com a utilização de uma adaptação da escala SERVQUAL. Também Allen Gonzalez, Gândara e Fraiz Brea (2006) Usaram uma adaptação do modelo SERVQUAL para analisar a influência que a qualidade percebida e a satisfação tem nas intenções do comportamento nos balneários da Espanha. Mamede e Veiga Neto (2011) analisaram e compararam as expectativas e a qualidade percebida por turistas brasileiros e estrangeiros em relação aos equipamentos e serviços turísticos de sol e praia usando o modelo SERVQUAL com cinco GAPs e a escala de Likert com pontos que variam de 1 a 5 e modificações que a tornaram mais simples, resultando na criação de uma escala própria denominada "SERVQUAL-TUR". Souza, Meira, Maske (2012) fizeram uma adaptação do referido modelo para medir e comparar o grau de importância 
(qualidade esperada) com a satisfação do cliente (qualidade percebida) em quatro hotéis de diferentes categorias de Balneário Camboriú/SC.

Ressalta-se que esses estudos foram realizados aplicando-se questionários aos entrevistados, mas com a chegada da internet e, principalmente, das redes sociais, onde as informações sobre experiências de viagem são compartilhadas livremente, tornou-se possível analisar a experiência turística usando como campo de estudos websites como Trivago, Booking.com e TripAdvisor. Gândara, Fraiz Brea e Manosso (2013) discutiram o turismo de saúde a partir da análise do turismo termal para compreender a qualidade das experiências vividas pelos hóspedes nos estabelecimentos termais, fazendo um estudo de caso dos balneários da Galícia - Espanha por meio da reputação online. Já Limberger, Boaria e Anjos (2014) utilizaram a website TripAdvisor para analisar as variáveis da satisfação que influenciam a satisfação geral em hotéis de excelência, além de buscar entender se existe diferença entre as influências dependendo da tipologia hoteleira (LIMBERGER, BOARIA e ANJOS, 2014). Também o estudo de Quiroga, Mondo e Castro Júnior (2014) abordou a reputação online como instrumento para melhoria de serviços na hotelaria de Garopaba e Imbituba - SC. Manosso, Silva, Bizinelli e Gândara (2016) também se basearam no modelo SERVQUAL para compreender a lógica do consumo que se materializa nos spas vinoterápicos pertencentes à Rede Caudalie por meio da website TripAdvisor.

As experiências dos clientes, com a chegada das redes sociais, têm sido compartilhadas com um grande número de pessoas. Para Montardo (2010) o conteúdo gerado pelo consumidor se caracteriza pela produção, armazenamento e distribuição de informações e opiniões sobre produtos, serviços e marcas na Web e esse fato é cada vez mais observado pela importância que os comentários no contexto da reputação das marcas vêm ganhando na perspectiva da informação (Guzmán et al, 2011). 


\section{A EXPERIÊNCIA DO HÓSPEDE E A REPUTAÇÃO ONLINE}

O comportamento do consumidor vem mudando com o passar do tempo. Atualmente ele não compra apenas para atender as suas necessidades, mas o consumo está relacionado aos sentimentos e emoções, ou seja, pela experiência que tal produto ou serviço proporciona (PINE II \& GILMORE, 1999; BIZINELLI et al., 2013). Compreende-se por experiência um acontecimento subjetivo que gera uma transformação no sujeito, sendo que durante a imersão, a ênfase deve ser nas emoções e no estímulo dos sentidos (CARU e COVA, 2003). "A perspectiva da qualidade na prestação dos serviços impacta diretamente na qualidade da experiência turística" (BIZINELLI et al., 2013, p. 353). Moital (2012) afirma que a experiência está centrada no consumidor, ou seja, em sua experiência emocional e nos significados a ela relacionados (MANOSSO, SILVA, BIZINELLI e GÂNDARA, 2016).

Schmitt (1999) e Pine II e Gilmore (1999) definem que uma boa experiência torna-se memorável ou extraordinária quando permite que 0 consumidor explore todos os seus sentidos. Os autores Holbrook (2000) e Barbosa, Souza, Kovacs e Melo (2011) defendem que naquelas ações dominadas pelas experiências a tomada de decisão do indivíduo pode se dar torno do imaginário, das emoções e do hedonismo, e nesse sentido, devem ser analisadas quatro questões na produção das experiências, a saber: 1) a 'experiência' que se unifica com a evasão da vida cotidiana, das emoções e do prazer; 2) o 'divertimento' representado pelo ambiente, que contribui para que a experiência se torne uma espécie de espetáculo; 3) o 'exibicionismo' onde se destaca o serviço que é mostrado ao consumidor por meio da realidade física; e 4) o 'evangelismo' que se refere ao conteúdo funcional (rapidez nos serviços), juntamente com uma função hedonista (cortesia dos funcionários) que um produto ou serviço pode possuir (MANOSSO et al 2016).

$\mathrm{Na}$ tentativa de melhor compreender a perspectiva da experiência turística, Pine $\|$ e Gilmore (1999) desenvolveram um estudo com quatro variáveis: entretenimento, aprendizagem, estética e evasão, chamado Domínios da Experiência. Para eles uma experiência significativa (memorável) 
surge a partir desses elementos, onde: 1) o Entretenimento é um aspecto mais passivo da experiência que oferece a diversão e a criação de lembranças a partir dos momentos vividos diante dos elementos que lhes são apresentados; 2) a Aprendizagem permite o turista aprender algo e requer total participação do indivíduo, envolve as perspectivas sensorial e intelectual; 3) a Estética ou Contemplação possibilita o encantamento visual, a contemplação, a beleza. Tem relação com a vontade do indivíduo em permanecer em determinado ambiente; 4) a Evasão conduz o visitante à imersão na atividade proposta e à perda da noção do tempo por sua capacidade de envolvimento relacionado à emoção e aos sentidos. (PINE II \& GILMORE, 1999).

A Figura 1 representa os domínios da experiência de Pine e Gilmore (1999), onde estão destacados dois eixos que compreendem o grau de participação e o grau de ligação do consumidor em relação à experiência turística: o eixo horizontal que exibe o seu grau de participação na experiência - ativa ou passiva, e o eixo vertical que representa o grau de ligação dele com a experiência, variando desde absorção, que é a atenção mental das pessoas, até a imersão, que conta com a presença física do indivíduo durante a experiência. Segundo o estudo, um serviço de qualidade, para tornar-se uma experiência inesquecível, deve conter os quatro Domínios da Experiência. (PINE II \& GILMORE, 1999)

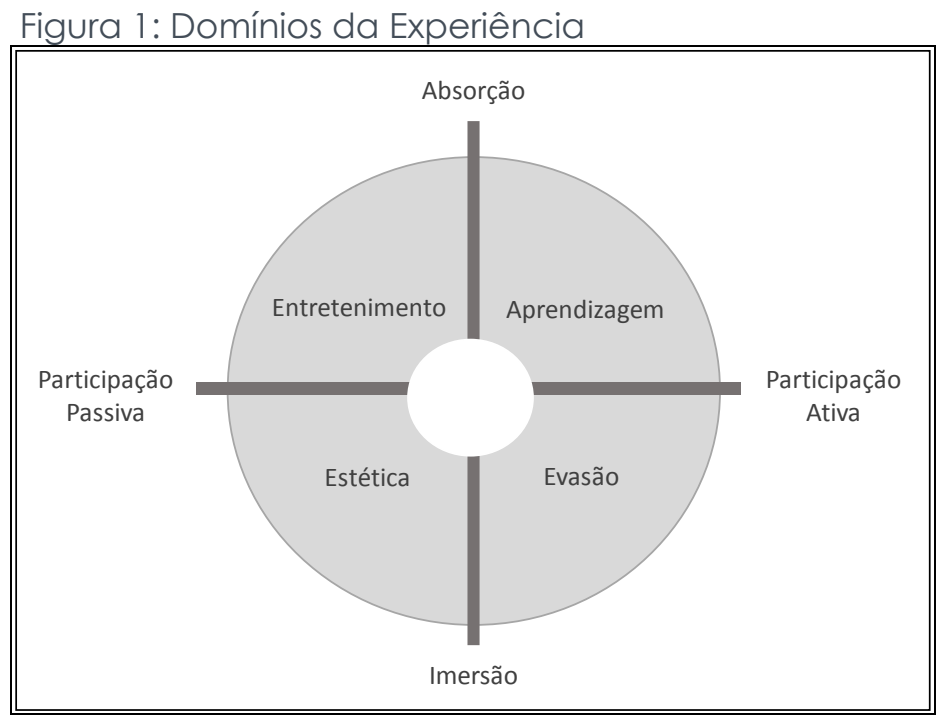

Fonte: Os autores (2016), adaptado de Pine II \& Gilmore (1999). 
A partir desse entendimento percebe-se a importância de considerar a avaliação do consumidor sobre o serviço recebido porque as expectativas e percepções são únicas para cada indivíduo. Então a satisfação do hóspede é considerada por Gândara, Fraiz Brea e Manosso (2013) um componente primordial para a qualidade da experiência e desse modo a qualidade e a satisfação se encontram intrinsicamente relacionadas, sendo a qualidade a estratégia chave para gerar satisfação no cliente. Os autores afirmam que "a qualidade da experiência turística está centrada nas histórias e experiências vividas" (GÂNDARA, FRAIZ BREA e MANOSSO, 2013, p. 499). Sendo assim, é cada vez mais perceptível a preocupação dos empreendimentos hoteleiros com a qualidade dos serviços oferecidos aos seus clientes para que a sua experiência seja satisfatória.

A informação é uma das principais estratégias para a tomada de decisão dos consumidores (BIZINELLI et al, 2013) e com o aumento do acesso à internet e, principalmente, a criação das redes sociais, o conteúdo gerado pelo consumidor (consumer generated content - CGC) que se refere à produção, armazenamento e distribuição da informação e de opiniões sobre produtos e serviços consumidos tem sido considerável (MONTARDO, 2010; GÂNDARA, FRAIZ BREA e MANOSSO, 2013; BIZINELLI et al, 2013). Vickery e Wunsch-Vincent (2007) relatam que o conteúdo gerado pelo consumidor se define como aquele conteúdo disponibilizado na internet que reflete um certo esforço criativo e que é criado fora das práticas e rotinas profissionais.

Websites e mídias sociais são ferramentas que permitem a busca de informações sobre os empreendimentos no ambiente online e interferem na escolha e na captação de clientes (GÂADARA, FRAIZ BREA e MANOSSO, 2013; BIZINELLI et al, 2013). Websites são entendidas como uma coleção estruturada de páginas da web (álbuns ou portfólio) que representam empresas ou pessoas, sendo acessadas pelo consumidor como fontes de informações a respeito de algum produto, serviço ou empreendimento (PANTELIDIS, 2010 apud BIZINELLI et al, 2013).

\footnotetext{
"Websites dos empreendimentos e sites de opinião devem ser considerados plataformas dinâmicas que permitam que os usuários compartilhem suas experiências com os outros e dessa
} 
maneira, o emprego da web se torna relevante, devido à riqueza do que está sendo postado, podendo influenciar de maneira direta no comportamento do consumidor, especialmente, na tomada de decisão". (RODRíGUEZ, 2009; MIGUÉNS, BAGGIO E COSTA, 2009 apud BIZINELLI et al, 2013, p. 356)

"Não há nada que inspire mais confiança do que a opinião do cliente que consumiu o produto ou serviço em questão, e que tem conhecimento de causa quando publica seus comentários" (FRIEDLANDER, 2012 apud BIZINELLI et al, 2013, p. 356). O autor também ressalta que os empreendimentos turísticos com reputação online positiva são aqueles que acompanham os comentários postados na web e que os consideram nas suas operações e decisões gerenciais. Essa constatação faz com que a opinião dos consumidores sobre as experiências e satisfação propagada nos meios virtuais seja de extrema relevância, por contribuir para a reputação do negócio (GÂNDARA, FRAIZ BREA E MANOSSO, 2013).

Reputação online é entendida como "a consequência da avaliação do mundo social na rede e, portanto, pode ser considerada como a mais autêntica, transparente, visível e, também, incontrolável, pois somente podese monitorá-la" (CUENLLAS, 2012 apud GÂNDARA, FRAIZ BREA e MANOSSO, 2013; BIZINELLI et al, 2013)

\section{METODOLOGIA}

Numa pesquisa netnográfica, entendida como aquela realizada pela internet, no caso deste estudo através da website TripAdvisor, buscando pelo nome spa no município de Foz do Iguaçu, foram encontrados seis empreendimentos que se justificam como spas pelos serviços, atrativos e terapias que oferecem e cujas descrições a seguir tem como fonte a página na web de cada resort: o Mabu Thermas Grand Resort que possui piscinas e praia de águas termais, além do Spa Corpo e Mente que oferece massagens, hidromassagens, terapias vibracionais, com pedras quentes; saunas seca e úmida e ofurô. $\bigcirc$ Bourbon Cataratas Convention \& Spa Resort abriga o Mandí Nature Spa com salas de massagens, menu de tratamentos e terapias, sauna 
e ducha. O Nadai Confort Hotel \& SPA oferece drenagem, massagens relaxantes e tratamentos para promover o equilíbrio entre o corpo e a mente. O Recanto Cataratas Thermas Resort \& Convention conta com o Java Jiwa SPA by $B$. Well que oferece massagens energizantes ou relaxantes, terapia vibracional e reflexologia, shiatzu e zen shiatzu, ofurô, cromoterapia e outros tratamentos corporais. O San Martin Resort \& Spa possui piscina, hidromassagem e saunas com ambiente climatizado e serviços personalizados. E por fim, o Belmond Hotel das Cataratas que oferece no seu spa tratamentos faciais, massagens, deep andiroba, com pedras quentes, drenagem linfática, esfoliação com massagem, além de tratamentos para o couro cabeludo, detox terapia com argila e banhos de imersão. Como o turismo de saúde de bem-estar engloba as atividades ligadas a água, ao relaxamento e a qualidade de vida, esses seis empreendimentos descritos acima foram considerados nessa pesquisa.

Para analisar a reputação online no website TripAdvisor dos spas de Foz do Iguaçu-PR, quanto à experiência e satisfação dos clientes em relação à qualidade, seguiu-se o método elaborado por Gândara, Fraiz Brea e Manosso (2013) a respeito da análise da qualidade da experiência dos hotéis termais localizados na Galícia (Espanha) e por Manosso et al (2016) sobre os spas vinoterápicos, desenvolvido a partir dos Domínios da Experiência de Pine II \& Gilmore (1999): 1. Estética (elementos que fazem com que o indivíduo tome a decisão de entrar em um local e ali permanecer), 2. Evasão (capacidade de fazer com que o consumidor fique imerso nas atividades que the são propostas), 3. Aprendizagem (essencialmente ativa, pois aprender algo requer total participação do sujeito envolvido e envolve tanto a perspectiva sensorial quanto intelectual) e 4. Entretenimento (aspecto mais passivo da experiência, pois designa um estado de resposta aos elementos que lhe são apresentados); também do método criado por Parasuraman, Zeithaml \& Berry $(1988$; 1994) chamado SERVQUAL, que considera cinco domínios: Tangibilidade, Confiabilidade, Disponibilidade, Segurança e Empatia, e mais 22 itens, e considerando ainda a adaptação feita por Costa \& Rita (2010) y Blešiš et al (2011) baseada nos mesmos conceitos e conhecida como HOTELQUAL com 
24 itens para a hotelaria. Logo, com base nos aspectos tratados nos artigos anteriores, fez-se uma adaptação para a análise dos referidos spas de Foz do Iguaçu.

A Tabela 1 apresenta as categorias de análise empregadas para a análise dos comentários.

Tabela 1: Categorias de Análise da Experiência nos spas de Foz do Iguaçu-PR

\begin{tabular}{|c|c|c|}
\hline Dimensões da Experiência & Categoria & Aspectos Analisados \\
\hline \multirow{4}{*}{ Estética: } & Paisagem & Vista \\
\hline & Edifício & Decoração/Arquitetura/Ambiente \\
\hline & Limpeza & \\
\hline & Entorno & $\begin{array}{l}\text { Oferta de produtos e serviços na } \\
\text { região }\end{array}$ \\
\hline \multirow{4}{*}{$\begin{array}{c}\text { Elementos que fazem com que o } \\
\text { indivíduo tome a decisão de } \\
\text { entrar em um local e ali } \\
\text { permanecer. }\end{array}$} & Localização & \\
\hline & Quartos & \\
\hline & $\begin{array}{l}\text { Instalações do } \\
\text { Hotel }\end{array}$ & Infraestrutura \\
\hline & Preço & Hotel/Restaurante/Terapias \\
\hline \multirow[t]{2}{*}{ Evasão: } & Conforto & \\
\hline & Restaurante & Qualidade/Variedade \\
\hline \multirow{4}{*}{$\begin{array}{l}\text { Capacidade de fazer com que o } \\
\text { consumidor fique imerso nas } \\
\text { atividades que lhe são propostas. }\end{array}$} & Facilidades & Wifi/Estacionamento/Amenidades \\
\hline & Informações & \\
\hline & Horários & Restaurante/Atividades/Terapias \\
\hline & Serviços & Transporte/Room Service \\
\hline Aprendizagem: & Funcionários & Atendimento \\
\hline $\begin{array}{l}\text { Essencialmente ativa, pois } \\
\text { aprender algo requer total } \\
\text { participação do sujeito } \\
\text { envolvido. Envolve tanto a } \\
\text { perspectiva sensorial quanto } \\
\text { intelectual. }\end{array}$ & Atividades & Jogos/Recreação/Passeios \\
\hline \multirow{4}{*}{$\begin{array}{c}\text { Entretenimento: } \\
\text { Aspecto mais passivo da } \\
\text { experiência, pois designa um } \\
\text { estado de resposta aos } \\
\text { elementos que Ihe são } \\
\text { apresentados. }\end{array}$} & $\begin{array}{l}\text { Terapias/ } \\
\text { Tratamentos }\end{array}$ & Banhos/Massagens \\
\hline & SPA & Instalações/Atendimento \\
\hline & Atrativos & Piscinas/Academia/Sauna \\
\hline & Espaço Kids & \\
\hline
\end{tabular}

Fonte: Elaborado pelos autores (2016), adaptado de Gândara, Fraiz Brea e Manosso (2013)

A partir da definição dos empreendimentos e das categorias de análise acima obteve-se o número total de comentários dos hóspedes postados entre 01/07 a 31/07/2015 pelos usuários da website TripAdvisor em cada spa, conforme se apresenta na Tabela 2. 


\section{APRESENTAÇÃO, ANÁLISES E DISCUSSÃO DOS RESULTADOS}

As primeiras análises apresentam o número total de avaliações positivas e negativas em relação à satisfação dos hóspedes por spa, considerando o comentário de cada hóspede que foi categorizado de acordo com os aspectos acima descritos, também apresentados na Tabela 2.

Tabela 2: Número total de avaliações, avaliações positivas e negativas por empreendimento

\begin{tabular}{|lccc|}
\hline Nome do SPA & $\begin{array}{c}\text { Total de } \\
\text { Comentários }\end{array}$ & $\begin{array}{c}\text { Avaliações } \\
\text { Positivas }\end{array}$ & $\begin{array}{c}\text { Avaliações } \\
\text { Negativas }\end{array}$ \\
\hline Mabu Thermas Grand Resort & 90 & 375 & 137 \\
\hline $\begin{array}{l}\text { Bourbon Cataratas Convention \& Spa } \\
\text { Resort }\end{array}$ & 36 & 177 & 19 \\
\hline Nadai Confort Hotel \& SPA & 20 & 116 & 19 \\
\hline $\begin{array}{l}\text { Recanto Cataratas Thermas Resort \& } \\
\text { Convention }\end{array}$ & 55 & 246 & 78 \\
\hline San Martin Resort \& Spa & 2 & 11 & 2 \\
\hline Belmond Hotel das Cataratas & 15 & 79 & 14 \\
\hline
\end{tabular}

Fonte: Elaborado pelos autores (2016)

Explica-se que o Total de Comentários se refere à quantidade total de comentários encontrados no TripAdvisor durante o mês de julho para cada meio de hospedagem. Os números nas colunas de Avaliações Positivas e Negativas se deram a partir da soma de avaliações positivas e negativas que cada comentário apontou, porque um único comentário normalmente apresenta vários aspectos positivos e/ou negativos.

A seguir, na Tabela 3, são apresentados os dados resultantes das análises positivas e negativas do TripAdvisor por categoria, por spa.

Tabela 3: Comentários positivos (P) e negativos (N) do TripAdvisor por categoria, por spa

\begin{tabular}{|c|c|c|c|c|c|c|c|c|c|c|}
\hline & \multicolumn{2}{|c|}{ Paisagem } & \multicolumn{2}{|c|}{ Edifício } & \multicolumn{2}{|c|}{ Limpeza } & \multicolumn{2}{|c|}{ Entorno } & \multicolumn{2}{|c|}{ Localização } \\
\hline & $P$ & $N$ & $P$ & $N$ & $P$ & $N$ & $P$ & $N$ & $P$ & $N$ \\
\hline Mabu & 6 & 1 & 8 & 1 & 18 & 7 & 2 & - & 13 & 3 \\
\hline Bourbon & 3 & - & 3 & - & 7 & - & 3 & - & 10 & - \\
\hline Nadai & - & - & 3 & - & 7 & 1 & 12 & - & 17 & - \\
\hline Recanto & 4 & 2 & 12 & - & 21 & - & 3 & - & 10 & 7 \\
\hline San Martin & 1 & - & - & - & - & - & 1 & - & 1 & - \\
\hline \multirow[t]{4}{*}{ Belmond } & 9 & - & 5 & - & - & - & - & 1 & 7 & 1 \\
\hline & 23 & 3 & 31 & & 53 & 8 & 21 & 1 & 57 & 11 \\
\hline & \multicolumn{2}{|c|}{ Quartos } & \multicolumn{2}{|c|}{ Instalações } & \multicolumn{2}{|c|}{ Preço } & \multicolumn{2}{|c|}{ Conforto } & \multicolumn{2}{|c|}{ Restaurante } \\
\hline & $P$ & $N$ & $P$ & $N$ & $P$ & $N$ & $P$ & $N$ & $P$ & $N$ \\
\hline Mabu & 38 & 5 & 22 & 13 & - & 28 & 22 & 2 & 44 & 17 \\
\hline Bourbon & 13 & - & 13 & - & 3 & 3 & 11 & 2 & 22 & 2 \\
\hline Nadai & 10 & 5 & 5 & 2 & 5 & - & 8 & 1 & 14 & 2 \\
\hline
\end{tabular}




\begin{tabular}{|c|c|c|c|c|c|c|c|c|c|c|}
\hline Recanto & 30 & 2 & 15 & 2 & 5 & 17 & 8 & 3 & 25 & 16 \\
\hline San Martin & 1 & - & 2 & - & 1 & - & 1 & 1 & - & 1 \\
\hline Belmond & 7 & - & 6 & 1 & - & 2 & 3 & - & 8 & 4 \\
\hline & 99 & 12 & 63 & 18 & 14 & 50 & 53 & 9 & 113 & 42 \\
\hline & \multicolumn{2}{|c|}{ Facilidades } & \multicolumn{2}{|c|}{ Informações } & \multicolumn{2}{|c|}{ Horários } & \multicolumn{2}{|c|}{ Serviços } & \multicolumn{2}{|c|}{ Funcionários } \\
\hline & $P$ & $\mathrm{~N}$ & $P$ & $N$ & $P$ & $N$ & $P$ & $\mathrm{~N}$ & $P$ & $N$ \\
\hline Mabu & 7 & 15 & 1 & 7 & 2 & 2 & 10 & 24 & 58 & 6 \\
\hline Bourbon & 5 & 2 & - & - & 2 & 4 & 6 & 1 & 24 & 1 \\
\hline Nadai & 8 & 1 & - & 1 & - & - & 1 & 1 & 11 & - \\
\hline Recanto & 5 & 15 & - & 1 & - & - & 8 & 8 & 34 & - \\
\hline San Martin & 1 & - & - & - & - & - & - & - & - & - \\
\hline \multirow[t]{4}{*}{ Belmond } & 4 & 1 & - & - & 4 & 1 & 9 & 2 & 7 & - \\
\hline & 30 & 34 & & 9 & 8 & 7 & 34 & 36 & 134 & 7 \\
\hline & \multicolumn{2}{|c|}{ Atividades } & \multicolumn{2}{|c|}{ Terapias } & \multicolumn{2}{|c|}{ Spa } & \multicolumn{2}{|c|}{ Atrativos } & \multicolumn{2}{|c|}{ Espaço Kids } \\
\hline & $P$ & $N$ & $P$ & $N$ & $P$ & $N$ & $P$ & $N$ & $P$ & $N$ \\
\hline Mabu & 36 & 9 & 1 & - & 8 & - & 52 & 3 & 18 & 3 \\
\hline Bourbon & 22 & 1 & 1 & - & 2 & - & 10 & 4 & 14 & - \\
\hline Nadai & 1 & - & - & 1 & 2 & 1 & 10 & 3 & 2 & - \\
\hline Recanto & 22 & 2 & 1 & - & 3 & - & 31 & 3 & 9 & - \\
\hline San Martin & 1 & - & - & - & - & - & 1 & - & - & - \\
\hline Belmond & 2 & - & - & - & - & - & 8 & - & - & 1 \\
\hline
\end{tabular}

Fonte: Elaborado pelos autores (2016).

Para avaliar a relevância de cada categoria de análise somou-se o número de comentários negativos e positivos por categoria em todos os spas, obtendo-se a seguinte situação:

Tabela 4: Total de comentários positivos e negativos por categoria

\begin{tabular}{|lccc|}
\hline \multicolumn{1}{c}{ Categoria } & Positivos & Negativos & Somatório \\
\hline Paisagem & 23 & 3 & 26 \\
\hline Edifício & 31 & 1 & 32 \\
\hline Limpeza & 53 & 8 & 61 \\
\hline Entorno & 21 & 1 & 22 \\
\hline Localização & 57 & 11 & 68 \\
\hline Quartos & 99 & 12 & 111 \\
\hline Instalações do Hotel & 63 & 18 & 81 \\
\hline Preço & 14 & 50 & 64 \\
\hline Conforto & 53 & 9 & 62 \\
\hline Restaurante & 113 & 42 & 155 \\
\hline Facilidades & 30 & 34 & 64 \\
\hline Informações & 1 & 9 & 10 \\
\hline Horários & 8 & 7 & 15 \\
\hline Serviços & 34 & 36 & 70 \\
\hline Funcionários & 134 & 7 & 141 \\
\hline Atividades & 84 & 12 & 96 \\
\hline Terapias/Tratamentos & 1 & 1 & 2 \\
\hline SPA & 15 & 1 & 16 \\
\hline Atrativos & 112 & 13 & 125 \\
\hline Espaço Kids & 43 & 4 & 47 \\
\hline Fonte: & 12016 & & \\
\hline
\end{tabular}

Fonte: Elaborado pelos autores (2016). 
A partir do que foi apresentado nos procedimentos metodológicos serão discutidos no próximo tópico os resultados provenientes das análises para o alcance do objetivo proposto.

Dos empreendimentos avaliados, observa-se na tabela 4 que a maior parte dos comentários postados na rede social TripAdvisor no período estudado são positivos, ressaltando-se que a qualidade empregada nesses meios de hospedagem está influenciando positivamente na experiência dos hóspedes, apoiando-se no conceito de qualidade como sendo o resultado da comparação entre a expectativa pelo serviço a ser recebido e a percepção daquilo que the foi entregue (PARASURAMAN, ZEITHAML \& BERRY, 1988; GRÖNROOS, 1988; BIZINELLI et al, 2013).

O destaque fica com o aspecto Funcionários relacionado à dimensão Aprendizagem que, como esclarecem Gândara, Fraiz Brea e Manosso (2013) é uma dimensão essencialmente ativa que se relaciona com aquilo que o empreendimento quer que o hóspede aprenda e absorva durante a estada, levando consigo algo vivido no meio de hospedagem. Castelli (2003) ressalta que as empresas prestadoras de serviços devem apostar fundamentalmente na qualidade do elemento humano, já que a excelência do serviço depende de como esses colaboradores se relacionam com os clientes.

Os itens que se diferem nesse aspecto, onde os comentários negativos superaram os positivos influenciando negativamente a reputação online dos spas, são Preço, Facilidades, Informações e Serviços. Os comentários relacionados ao preço, destacavam a questão custo/benefício, ou seja, sensação de pagar caro por algo sem qualidade, o que denota que a expectativa foi superior ao serviço recebido muito bem esclarecido por Parasuraman, Zeithaml \& Berry (1988), Grönroos (1988) e Gândara, Fraiz Brea e Manosso (2013) quando afirmam que a qualidade é o resultado da comparação entre a expectativa pelo serviço a ser recebido e a percepção desse serviço recebido. Nota-se que preço está associado à estética que se relaciona com a tomada de decisões do consumidor e com a vontade do indivíduo em permanecer em determinado ambiente (PINE II \& GILMORE, 1999; GÂNDARA, FRAIZ BREA e MANOSSO, 2013). Wanderlei (2004) ressalta que 
com o aumento do uso da internet como ferramenta de pesquisa prévia sobre preços e serviços, o consumidor pode fazer uma comparação entre os empreendimentos, que influencia sua decisão positiva ou negativamente. Spolon (2009) lembra que se se todos os aspectos que levam à satisfação do consumidor são atendidos de forma positiva, o preço se torna irrelevante, já que a experiência vivida pelo hóspede foi significativa.

Facilidades, Informações e Serviços referem-se à Evasão que conduz o visitante à imersão na atividade proposta e à perda da noção do tempo por sua capacidade de envolvimento relacionado à emoção e aos cinco sentidos humanos (PINE II \& GILMORE, 1999; GÂNDARA, FRAIZ BREA e MANOSSO, 2013). São componentes importantes para a experiência turística para que a mesma se converta em algo diferenciado e único. Para Carbone e Hackel (1994 apud GÂNDARA, FRAIZ BREA e MANOSSO, 2013) OS empreendimentos devem propor experiências para os consumidores como uma importante estratégia para estabelecer e manter a preferência do consumidor frente ao serviço oferecido.

Na Tabela 4 ressalta-se a relevância que os clientes atribuem às categorias analisadas, sendo restaurante o item com o maior número de avaliações (155 comentários), seguido de funcionários/atendimento e oferta de atrativos. Tais fatores fazem referência aos mesmos que impactaram significativamente na satisfação dos hóspedes quanto à qualidade dos serviços indicados por Qu, Ryan e Chu (2000) destacando-se o atendimento dos funcionários, as instalações e a variedade e eficiência dos serviços (DIAS e PIMENTA, 2005). Nesse contexto, ressalta-se a importância de se entender que a experiência é única e está relacionada aos sentimentos e emoções de cada indivíduo em cada situação (PINE II \& GILMORE, 1999 apud BIZINELLI et al., 2013)

O item spa não teve um volume significativo de comentários nessa pesquisa, ficando com a décima sétima posição das vinte categorias avaliadas, na frente apenas de terapias, informações e horários. A partir desse dado observa-se que os spas de Foz do Iguaçu se enquadram na categoria 
de resorts - hotéis em cujas instalações são oferecidos serviços de spa, como massagens, tratamentos de estética e banhos diferenciados orientados ao ócio, à beleza e ao relaxamento (CHON e SPARROWE, 2003; MTUR, 2010; BONFADA et al, 2011) sugerindo que o spa é mais uma atividade de entretenimento dentro do resort, assim como as piscinas, a recreação, os jogos e os passeios. Um único comentário abordou que escolheu o hotel em função do spa.

\section{CONSIDERAÇÕES FINAIS}

A qualidade na prestação dos serviços interfere na experiência e satisfação do usuário. As redes sociais são ferramentas cada vez mais usadas pelos usuários para compartilhar experiências de viagens onde os clientes podem expressar livremente sua opinião sobre os aspectos que mais thes agradaram ou desagradaram da sua vivência, não sendo pressionados por um entrevistador ou induzidos por alguma questão elaborada, conforme a afirmação de Friedlander (2012 apud BIZINELLI et al, 2013) "não há nada que inspire mais confiança do que a opinião do cliente que consumiu o produto ou serviço em questão, e que tem conhecimento de causa quando publica seus comentários". Sartori \& Reis (2010 apud GÂNDARA, FRAIZ BREA e MANOSSO, 2013) defendem que a opinião dos indivíduos sobre as experiências e a satisfação propagada nos meios virtuais se revela de extrema relevância, por contribuir para a reputação do negócio.

Qualitativamente, é nítido observar que quando o cliente está satisfeito, normalmente tece somente elogios a respeito do empreendimento e aquele insatisfeito aponta apenas os pontos negativos da empresa. Há um outro grupo (menor) de clientes que aproveita a rede social para elogiar alguns aspectos e solicitar melhorias em um ponto específico.

O que se pode observar com esse estudo é que o resultado sobre os comentários postados a respeito dos spas tratam muito mais de aspectos como alimentação, atendimento, atrações (infraestrutura e serviços) do que dos tratamentos relacionados ao bem-estar e à estética. Isso pode ser em função do período avaliado, pois julho é período de férias escolares e muitas 
famílias aproveitam para curtir esse período focando na diversão para as crianças, ou porque esses spas são entendidos pelos consumidores como mais uma opção de atividade de lazer (atrativo) dentro do resort, não configurando como principal motivação da viagem. Viu-se na pesquisa que, nas viagens em família, o item mais comentado sobre os atrativos do hotel estava relacionado à recreação e atividades para os filhos, não havendo muitas referências sobre as massagens e demais tratamentos para adultos. De qualquer forma, se faz importante uma investigação mais aprofundada sobre o tema, incluindo outros períodos do ano e a indagação aos responsáveis pela administração desses empreendimentos sobre a frequência e uso desses spas pelos seus clientes, e qual o grau de importância desse atrativo para a receita do resort.

As principais contribuições do método elaborado por Gândara, Fraiz Brea e Manosso (2013) é a análise integrada entre as quatro dimensões de Pine e Gilmore II (1999) com os itens voltados para a hotelaria que permitiram novas adaptações para o objeto do estudo (spas) e a sua aplicação nas redes sociais, não utilizando questionários o que possibilita uma análise mais neutra, sem a intervenção do pesquisador.

Outro fato relevante desse trabalho é que o campo de estudo (web) se mostrou apropriado para a pesquisa porque as redes sociais são usadas pelos usuários para compartilhar experiências de viagens onde os clientes expressam livremente sua opinião sobre os aspectos que mais Ihes agradaram ou desagradaram da sua vivência, sem a interferência do pesquisador e que o modelo teórico de Gândara, Fraiz Brea e Manosso (2013) que mistura SERVQUAL, HOTELQUAL e Domínios da Experiência se mostrou adequado à pesquisa, principalmente considerando não só a qualidade de serviços mas a qualidade da experiência como um todo.

Esse estudo espera contribuir para essa reflexão e outras abordagens sobre reputação online dos meios de hospedagem e estudos sobre qualidade, experiência e satisfação nos spas. 


\section{REFERÊNCIAS}

Agência de Desenvolvimento Turístico da Região Cataratas do Iguaçu e Caminhos ao Lago de Itaipu - ADETUR (2016). Foz do Iguaçu. Disponível em http://www.adeturcataratasecaminhos.org.br/municipio/foz-do-iguacu/.

Acesso em 18/01/2016

Albach, V.M. (2015) A difusão da pesquisa em Geografia do Turismo na Ibero-América. Curitiba-PR. Tese (doutorado em Geografia) - Programa de Pós-Graduação em Geografia, Universidade Federal do Paraná.

Allén Gonzalez, M. E. A.; Gândara, J. M. G.; Fraiz Brea, J. A. F. (2006) "Explicación de las intenciones de comportamiento a través de la calidad percibida y la satisfacción en el turismo termal de España". Revista Turismo em Análise, v. 17, n. 2, p. 206-224.

Alvarenga, L. (1998) Bibliometria e arqueologia do saber de Michel Foucault - traços de identidade teórico-metodológica. Ciência da Informação, vol. 27, n 3 .

Aragones, F. J. A.; Payares, A. M. C.; Navas, R. E. M. (2012) El turismo de salud: Conceptualización, historia, desarrollo y estado actual del mercado global. Clío América, Ano 6, N. 11, p. 72-98.

Associação Brasileira de Clínicas e Spas - ABC SPAs. (2015) Disponível em http://www.abcspas.com.br/sobre.asp. Acesso em 20/05/2015

Associação Brasileira de Turismo de Saúde - ABRATUS. (2015) Disponível em http://www.abratus.org.br/o-que-e-turismo-de-saude.php. Acesso em 22/02015

Barbosa, M. L. A.; Souza, A. G.; Kovacs, M. H. Melo, L. S. A. (2011) Gestão da Experiência de serviços de hospitalidade: o que a empresa propõe e qual o significado para o consumidor. Observatório de Inovação do Turismo, 06 (02), 01-15.

Bizinelli, C.; Manosso, F. C.; Gândara, J. M. G.; Valduga, V. (2013) Experiências de Turismo Cervejeiro em Curitiba, PR. Revista Rosa dos Ventos, 5(2), p.349-375.

Blešiš, I.; Ivkov-Dṭigurski, A.; Stankov, U.; Stamenkoviš, I. \& Bradiš, M. (2011) "Research of expected and perceived service quality in hotel management". Journal of tourism. Nro. 11:5-13.

Bonfada, M. R. H.; Bonfada, P. L. B.; Gândara, J. M. G; Fraiz Brea, J. A. (2008) Turismo Termal: Cambios Conceptuales Y Mercadológicos de los balneários en España. Revista Turismo Visão e Ação, v. 10, n. 03, p. 415-434.

Bonfada, M. R. H.; Bonfada, P. L. B.; Fraiz Brea, J. A.; Gândara, J. M. G. (2011) La importância de la cosmética termal para los balneários y el turismo termal: el caso de la Comunidad Autónoma de Galícia - España. Revista PASOS, vol. 09, n. 01, p. 25-35. 
Brasil. (2010) Cadernos de Orientações Básicas de Segmentos Turísticos Turismo de Saúde: orientações básicas. Brasília, DF: Ministério do Turismo.

Brasil. (2010) Sistema Brasileiro de Classificação de Meios de Hospedagem: cartilha de orientação básica - Resort. Brasília, DF: Ministério do Turismo.

Caru, A. \& Cova, B. (2003) "Revisiting consumption experience: a more humble but complete view of the concept". Marketing Theory, v. 3(2). p. 267286.

Castelli, G. (2003) Administração hoteleira. EDUCS, Caxias do Sul.

Chon, K.; Sparrowe, R. T (2003). Hospitalidade: conceitos e aplicações. São Paulo: Pioneira Thomson Learning.

Costa, J.; Salazar, A. \& Rita, P. (2010) "A service quality evaluation scale for the hospitality sector: Dimensions, Attributes and behavioral intentions". Worldwide Hospitality and Tourism Themes 2(4): 383-397.

Creswell, J. W. (2010) Projeto de pesquisa: métodos qualitativo, quantitativo e misto. 3 ed. Porto Alegre: Artmed.

Cronin J. \& Taylor, S. (1992) "Measuring service quality: a reexamination and extension". Journal of Marketing, vol. 56: 55-88.

Crosby, P.B. (1987) "La calidad no cuesta". México: CECSA.

Delgado, J. (1997) Sensibilização para a importância da Qualidade no mercado atual. Lisboa: Millenium online, Revista do ISPV, $\mathrm{n}^{\circ} 8$.

Dias, R. E Pimenta, M. A. (orgs). (2005) Gestão de Hotelaria e Turismo. São Paulo: Pearson Prentice Hall, 2005.

Dusseau, R.; Brennan, M. W. (2008) Spa feasibility: steps and processes. In: Cohen, M.; Bodeker, G. Understanding the global spa industry. Oxford: ButterworthHeinemann.

Ezaidi, A.; Kabbachi, B.; El Youssi, M. (2007) El patrimonio geológico de Marruecos: una potencialidad para el desarrollo de un turismo de salud, como factor de lucha contra la pobreza. Revista PASOS: Revista de Turismo y Patrimonio Cultural, 01. V. 5(3), pp.371-382.

Falces Delgado, C.; Sierra Diez, B.; Becerra Grande, A. L. \& Brinöl Turnes, P.(1999) "HOTELQUAL: Una escala para medir calidad percibida en servicios de alojamento". Estudios Turísticos, núm. 139: 95-110.

Flores, P. S. O. (2015) Treinamento e Qualidade em hotéis. Disponível em http://www.unimonte.br/news/828.asp. Acesso em 28/12/2015

Foz Do Iguaçu. Secretaria Municipal de Turismo de Foz do Iguaçu. (2012) Estudo da Demanda Turística Foz do Iguaçu, 2012. Disponível em http://www.turismo.pr.gov.brl, acesso em 01/12/2015

Gândara, J. M. G.; Fraiz Brea, J. A.; Manosso, F. C. (2013) Calidad de la experiencia en los hoteles termales de Galícia, España. Un análisis a través de 
la reputación online. Estudios y Perspectivas en Turismo. Cidade Autônoma de Buenos Aires, vol. 22, p. 492-525.

Getty, J. M. \& Thompson, K. N. (1994) "The relationship between quality, satisfaction, and recommending behavior in lodging decisions". Journal of Hospitality \& Leisure Marketing 2(3): 3-22.

Grönroos, C. (1988) "Service quality. The six criteria of good service quality" Review of Business, St. John University Press, New York 9(3): 10-13.

Guzmán, V.; Romero, N.; Cerrato, N.; García, B.; Rosado, E.; Manzano,I.; Vilchez, I. Rosas, S.; Del Campo, D. \& Montalvo, B. (2011) "Curso en community management". Fundación UNED, Madrid.

Harvey, D. (1996) Condição pós-moderna: uma pesquisa sobre as origens da mudança cultural. São Paulo: Loyola, 1996

Heyes, A.; Beard, C.; Gehrels, S. (2015) Can a luxury hotel compete without a spa facility? Opinions from senior managers of London's luxury hotels. Revista Hospitalidade. São Paulo, XII (Especial), 262 - 275.

Holbrook, M. B. (2000) The Millennial Consumer in the Texts of Our Times: Experience and Entertainment. Journal of Macromarketing, 20 (02), 178-192. Doi: $10.1177 / 0276146700202008$.

Hotel Mabu. (2016) Disponível em www.hoteismabu.com.br/hoteis/thermasresort. Acesso em 10/01/2016

Hotel Bourbon. (2016) Disponível em www.bourbon.com.br. Acesso em $10 / 01 / 2016$

Hotel Nadai Confort. (2016) Disponível em www.nadaiconforthotel.com.br/novo. Acesso em 10/01/2016

Hotel Recanto Cataratas. (2016) Disponível em www.recantocataratasresort.com.br. Acesso em 10/01/2016

Hotel San Martin. (2016) Disponível em www.hotelsanmartin.com.br. Acesso em 10/01/2016

Hotel Belmond. (2016) Disponível em www.belmond.com/pt-br/hotel-dascataratas-iguassu-falls. Acesso em 10/01/2016

Itaipu Binacional. (2015) De janeiro a julho, aeroporto de Foz teve movimento recorde (2015). Disponível em https://www.itaipu.gov.br/sala-deimprensa/noticia/de-janeiro-julho-aeroporto-de-foz-teve-movimento-recorde. Acesso em 29/11/2015

Juran, J.M.; Gryna, F.M. (1993) "Manual de control de la calidad". Madrid: McGraw-Hill.

Knutson, B.; Stevens, P.; Wullaert, C.; Patton, M. \& Yokoyama, F.(1990) "LODGSERV: A service quality index for the lodging industry". Hospitality Research Journal 14(2): 277-284. 
Limberger, P. F.; Boaria, F.; Anjos, S. J. G. (2014) A relação entre a satisfação geral e as variáveis da satisfação na hotelaria em hotéis de excelência. Revista Brasileira de Pesquisa em Turismo. São Paulo, 8(3), p. 435-455.

Mamede, M. I. B.; Veiga Neto, A. R. (2011) Qualidade percebida e expectativas de brasileiros e estrangeiros em relação aos equipamentos e serviços turísticos. Revista Turismo Visão e Ação - Eletrônica, Vol. 13, n 3, p. 311 328.

Manosso, F.C., Silva, D.S., Bizinelli, C. \& Gândara, J.M. (2016) Relações de consumo nas experiências enoturísticas: uma análise a partir de empreendimentos hoteleiros vinoterápicos. Tourism and Hospitality International Journal, 6(2), 107-125.

Martins, G. A.; Theóphilo, C. R. (2009) Metodologia da investigação científica para ciências sociais aplicadas. 2. Ed. São Paulo: Atlas.

Moital, M. (2012) "The Tourist Experience". Ourense: Master en Turismo, Universidad de Vigo.

Montardo, S. P. (2010) Conteúdo gerado pelo consumidor: reflexões sobre sua apropriação pela Comunicação Corporativa. Intercom - Revista Brasileira de Ciências da Comunicação, São Paulo, 33 (2), 161-180.

Oliver, R. (1981) "Measurement and evaluation of the satisfaction process in retail settings". Journal of Retailing, 57, 25-48.

Pacheco, G. J. A.; Rojas, H. R. G. G. (2014) Turismo de salud por medio del aprovechamiento de aguas termales. Caso de la Ruta de la Salud Michoacán. Revista Economía y Sociedad, v. XVIII, n. 31, p. 121-143 Universidad Michoacana de San Nicolás de Hidalgo Morelia, México.

Paixão, D. L. D. (2007) Thermae et ludus: o início do turismo de saúde no Brasil e no mundo. Revista Turismo em Análise, v. 18, n. 2, p. 133-147.

Paraná. Paraná Turismo. (2014) Paraná - Estudo Estatístico 20 Anos de Turismo. Disponível em http://www.turismo.pr.gov.br/arquivos/File/Parana_Estudo_Estatistico_20_ano s Turismo 1.pdf. Acesso em 08/12/2015.

Parasuraman, A.; Zeithaml, V.; Berry, L. (1985) "A conceptual model of service quality and its implications for future research". Journal of Marketing, 49(4), 41-50.

Parasuraman, A.; Zeithaml, V. \& Berry, L. (1988) "SERVQUAL: A multiple-item scale for measuring consumer perceptions of service quality." Journal of Retailing 64(1): 12-40.

Parasuraman, A., Zeithaml, V. \& Berry, L. (1994) "Reassessment of expectations as a comparison standard in measuring service quality: implications for further research". Journal of Marketing, jan, v. 58, n. 1, p.111124. 
Pine li, J.; Gilmore, J. H. (1999) The experience economy. Boston: Harvard School Press.

Qu, H.; Ryan, B.; Chu, R. (2000) The importence of hotel atributes in contributing to travelers satisfaction in the Hong Kong hotel industry. In: Journal of Quality Assurance in Hospitality \& Tourism. V. 1 (3).

Quiroga, R. M.; Mondo, T. S.; Castro Júnior, D. F. L. (2014) Reputação online como instrumento para melhoria de serviços: um estudo na hotelaria de Garopaba e Imbituba - Santa Catarina. Revista de Turismo Contemporâneo RTC, Natal, v. 2, n. 1, p. 95-112.

Reisinger, Y. (2001) "Unique Characteristics of Tourism, Hospitality, and Leisure Services". En: Service Quality Management in Hospitality, Tourism, and Leisure. Kandampully, J; Mok, C.; Sparks, B. New York: The Haworth Hospitality Pres.

Santomá Vicens, R.; Costa Guix, G. (2007) "Calidad de servicio en la industria hotelera: revisión de la literatura". Revista de Análisis Turístico, n 3, p. 27-44, ISSN: 1885-2564 Depósito Legal: B-39009. Asociación Española de Expertos Científicos en Turismo (AECIT).

Schmitt, B. H. (1999) "Experiential Marketing: How to Get Customers to Sense, Feel, Think, Act, Relate to Your Company and Brands". New York: The Free Press.

Souza, E. C.; Meira, J. V.De S.; Maske, D. C. (2012) A Medição da Qualidade dos Serviços Prestados em Hotéis de Balneário Camboriú, SC: Uma Aplicação do Modelo SERVQUAL. Revista Rosa dos Ventos, 4(IV), p. 544-555.

Spa Finder. (2015) "Trends Report - Top 10 Global Spa and Wellness Trends Forecast". Edited by: Susie Ellis, 2014. Disponível em http://www.spafinder.co.uk. Acesso em: 15/10/2015.

Spolon, A. (2009) Sobre os domínios da hospitalidade. VI Seminário ANPTUR. Anais. Aleph, São Paulo.

Stevens, P.; Knutson, B. \& Patton, M. (1995) "DINESERV: a tool for measuring service quality in restaurants". Cornell Hotel and Restaurant Administration Quarterly 36(2): 56-60.

Tafarelo, C. S. C. (2013) Análise Crítica entre Etnografia e Netnografia: métodos de pesquisa empírica. Artigo apresentado no evento $9^{\circ}$ Interprogramas de Mestrado em Comunicação da Faculdade Cásper Líbero. São Paulo.

Vargas, R. L.; Gil, A. Ma. L. (2002) Las estaciones termales en andalucía: de la explotación tradicional a la configuración de un nuevo producto turístico integral. Revista Cuadernos de Turismo, n. 10, p. 101-122. Universidad de Murcia Murcia, España.

Veiga, L. S.; Farias, J. S. (2005) Avaliação da qualidade dos serviços em uma pousada com a aplicação da escala SERVQUAL. Revista Turismo Visão e Ação, v. 7, n. 2, p. 257-272.

Vickery, G.; Wunsch-Vincent, S. (2007) Participative Web and User-Created Content. Web 2.0, Wikis and Social Network. Paris: OECD. 
Wanderlei, H. (2004) A percepção dos hóspedes quanto aos atributos oferecidos pelos hotéis voltados para o Turismo de Negócios na cidade de São Paulo. Dissertação apresentada para obtenção de título de Mestre em Engenharia na Escola Politécnica da Universidade de São Paulo, São Paulo. 